\title{
Partial discharge behaviour of biaxially orientated PET films: the effect of crystalline morphology
}

\author{
Rong Tang ${ }^{a, c}$, John J. Liggat ${ }^{a^{*}}$, Wah H. Siew ${ }^{b}$ \\ ${ }^{a}$ WestCHEM, Department of Pure and Applied Chemistry, University of Strathclyde, Glasgow, G1 1XL, \\ Scotland, United Kingdom. \\ ${ }^{b}$ Department of Electronic \& Electrical Engineering, University of Strathclyde, Glasgow, G1 1XW, \\ Scotland, United Kingdom.
}

\section{Abstract}

The relation between PD induced breakdown behaviour and crystalline and amorphous morphology of PET films used in photovoltaic devices has been explored and discussed in this work for the first time. Biaxially orientated PET films with and without $\mathrm{BaSO}_{4}$ filler were isothermally annealed at various temperatures before partial discharge (PD) breakdown tests of the films to investigate the crystalline morphology effect. Attenuated total reflectance - Fourier transform infrared spectroscopy (ATR-FTIR) and differential scanning calorimetry (DSC) were used to study the changes of crystallinity and lamellar thickness of the samples. It was found that both PD resistances and PD lifetimes could be significantly improved when the samples were annealed at temperatures above $210^{\circ} \mathrm{C}$. On the other hand, improvements were much less in the annealing temperature region between 180 to $210^{\circ} \mathrm{C}$. This is because the thinner and less perfect lamellae formed by annealing at the lower temperatures are less effective at resisting either ion bombardment or electrical tree propagation. On the other hand, the formation of thickened and perfected lamellae produced at higher annealing temperatures can effectively increase the tortuosity of electrical tree propagation paths, thereby increasing the PD lifetimes.

Key words: poly(ethylene terephthalate); photovoltaic; partial discharge; morphology; annealing.

*Corresponding author footnote: email: j.j.liggat@strath.ac.uk

${ }^{c}$ Current address: Shenzhen Key Laboratory of Advanced Thin Films and Applications, College of Physics and Energy, Shenzhen University, 518060, Shenzhen, China 


\subsection{Introduction}

Backsheet, the rearmost protection component of a photovoltaic (PV) module, not only provides electrical insulation for the module but also protects the active PV components from external degradative influences such as UV radiation and moisture. PV modules are typically expected to perform at least 25 years under long-term outdoor exposure and this would be impossible without proper backsheet material selection. Poor backsheet materials will deteriorate rapidly when they are subjected to harsh environments where strong UV radiation, moisture and high temperature are combined. In typical photovoltaic modules, a PET film (typically $250 \mu \mathrm{m}$ thick) is used alongside poly(vinyl fluoride) (PVF) as the core layer of a PVF/PET/PVF laminate backsheet. The PET provides the electrical insulation and mechanical properties whilst the PVF provides the environmental stability. During service, the backsheet materials are potentially subjected to voltages as high as $1000 \mathrm{~V}$, sufficiently high to initiate partial discharge (PD) in the backsheet due to pollutants and moisture on the backsheet surface [1]. PD is defined as 'a localized electrical discharge that only partially bridges the insulation' [2]. As a result, in most cases PD does not cause immediate system failure but degrades the insulation over time at a relatively slow rate. Energetic ion bombardment, excited molecules and high local temperatures generated by discharges will chemically and physically degrade and erode the material, ultimately leading to dielectric breakdown if no remedy is taken [3]. This undoubtedly poses a threat to the electrical load of the PV module as well as the safety of people who work with the module. Furthermore, trends are moving to thinner and lighter PV modules including the backsheets, which will be particularly challenging for the safe electrical operation of the module since the backsheets will be subjected to a higher electric field. The chemistry of electrical discharge-induced degradation of PET has been extensively studied using a number of surface analytical techniques such as ATR-FTIR, X-ray photoelectron spectroscopy (XPS), contact angle and atomic force microscopy (AFM) [4-6]. Chain scission occurs via the bombardment of energetic electrons and ions from the electrical discharge. Surface oxidation occurs with oxygen-containing polar groups such as carbonyl, aldehyde and carboxylic acid incorporated onto the sample surface, leading to an increase of hydrophilicity of the sample. SEM and AFM micrographs show surface erosion, which is the consequence of the ion and electron bombardment and surface decomposition due to localised high temperature. From the electrical engineering aspect, it was reported that thicker PET samples are more prone to suffering internal PD degradation than thin ones when they are subjected to identical electric field since voids whose size are big enough to initiate a local dielectric breakdown are more likely to exist in a thicker sample [7]. 
Backsheets are usually white because of the higher reflectance and efficiency. $\mathrm{BaSO}_{4}$ and $\mathrm{TiO}_{2}$ are two common fillers used in commercial PET films to increase the product's whiteness due to low cost and high refractive index, respectively. In addition, UV stabilizers are often used in the outer layered PET film of backsheets to provide UV stability. In our previous paper, four categories of biaxially oriented, semicrystalline PET films filled with different fillers and performance additives were examined. PET filled with $\mathrm{BaSO}_{4}$ or $\mathrm{TiO}_{2}$ were found to have better PD resistance than unfilled PET. Further improvements on PD resistance and PD lifetime were observed when the sample also contained a UV stabilizer [8].

As well as additives, polymer morphology may be expected to influence PD resistance although its influence has not been extensively studied $[9,10]$. Isothermal crystallization/annealing is a simple way to not only increase the crystallinity of a polymer material but also thicken and perfect the crystalline lamellae, thereby improving the material performance. For example, in order to improve the gas or moisture barrier properties of PET, samples are usually annealed at temperatures between the glass transition temperature $T_{g}$ and the melting point $T_{m}$ to increase the crystal size [11]. Therefore, whether the PD resistance and PD lifetime of PET materials can also be improved via annealing treatments is an interesting and open question that we address in this paper.

\section{Experimental}

\subsection{Samples}

A biaxially oriented PET without any additives (PET) and a biaxially oriented PET filled with $18 \% \mathrm{BaSO}_{4}$ and with $1.0 \%$ Tinuvin 1577 UV stabilizer (PET-BaSO ${ }_{4}$ UV) were provided by DuPont Teijin Films and were both of $50+/-1 \mu \mathrm{m}$ thickness.

\subsection{Annealing treatments of samples}

Before any PD or dielectric breakdown test, the above mentioned samples were isothermally annealed at various temperatures from 180 to $230^{\circ} \mathrm{C}$ in a laboratory oven for one hour. After cooling, all the samples thicknesses were measured by using a digital micrometer to determine whether sample thickness changes had occurred during the annealing processes. No changes were noted. 


\subsection{Experimental set-up of partial discharge and breakdown tests}

Partial discharge breakdown experiments were conducted using the IEC (b) electrode system according to IEC 60343. The electrode system consists of rod and plane stainlesssteel electrodes where the rod electrode has an end curvature of $1 \mathrm{~mm}$ radius (Fig. 1). The whole system was enclosed in a PMMA tube in which silica gel was used to keep the relative humidity as low as possible. The temperature, $20 \pm 2^{\circ} \mathrm{C}$, was not specifically controlled during experiments.

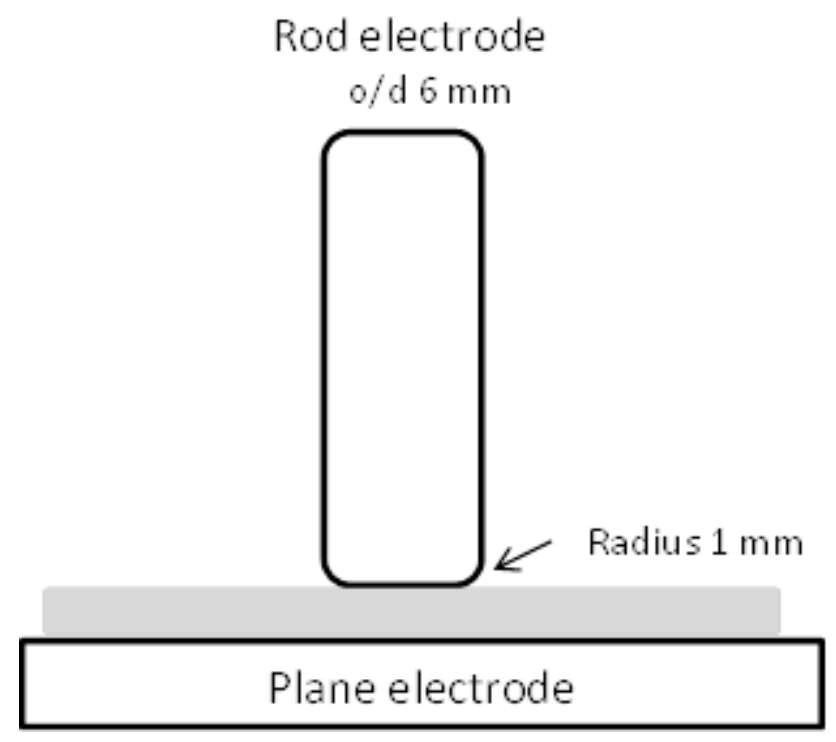

Figure 1: Schematic diagram of IEC (b) electrode system

\subsubsection{Experimental set-up for PD exposure tests}

For the samples with different additives, two sample stacks with identical thickness $(250 \mu \mathrm{m})$ were subjected to a $50 \mathrm{~Hz}$ AC high voltage of $3 \mathrm{kV}$ for 24 hours. The schematic of the whole experimental set-up is shown in figure 2 , the annealed samples were placed on the top layer of each stack (black block in figure 2) while the other sheets of the stacks being the untreated samples. After PD exposure only the upper side of the top sheet showed any visible sign of damage (the sample surface became white and rough around the electrode contact area) and only this surface was subjected to further analysis. Figure 3 shows an SEM image of a PET film post-exposure showing the typical damage. 


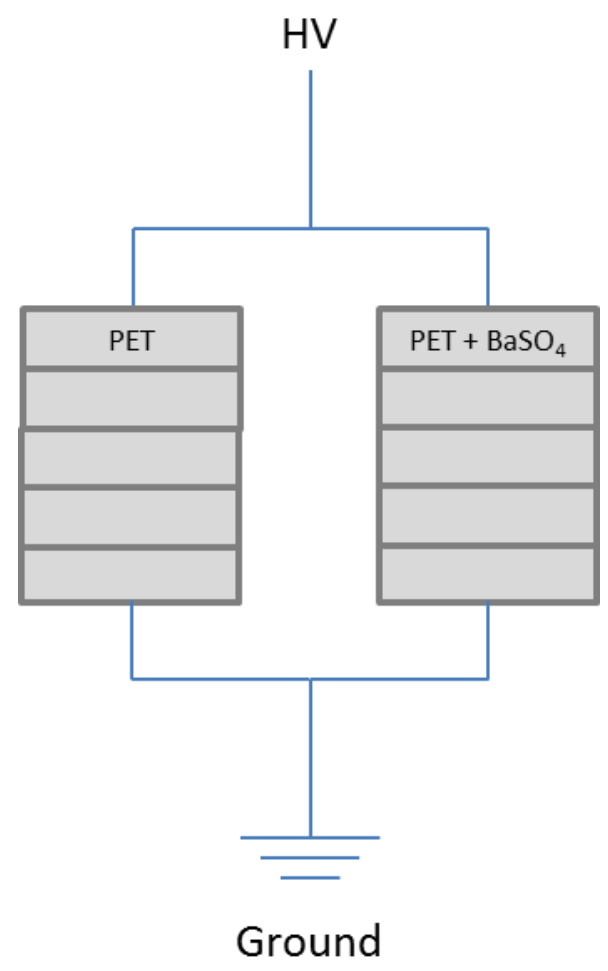

Figure 2: Schematic of set-up for PD exposure of samples after annealing treatment

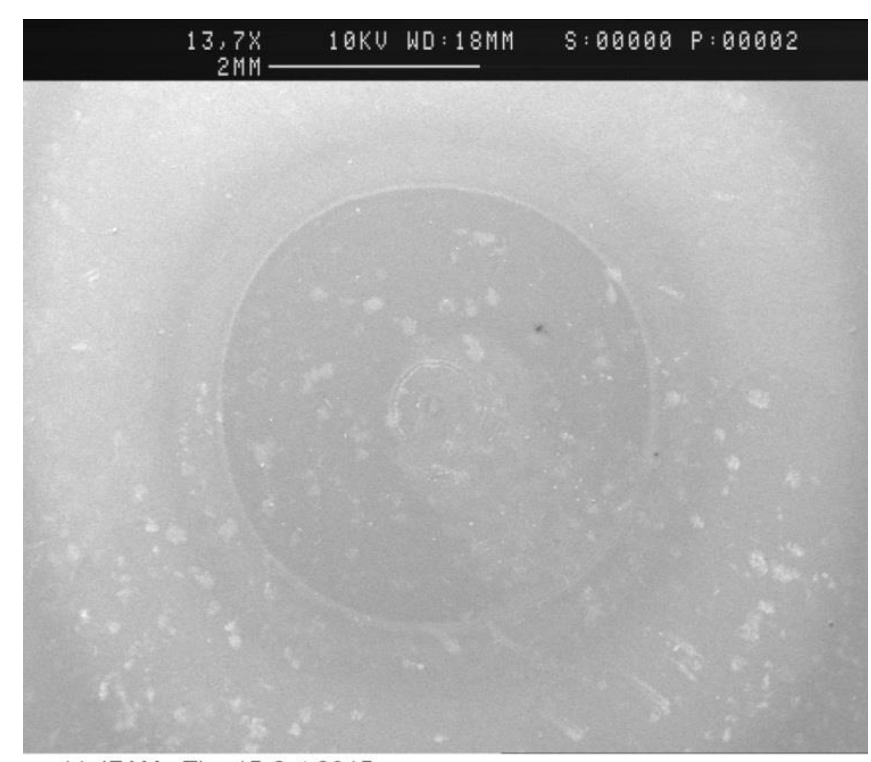

11:47AM Thu 15 Oct 2015

Figure 3: Scanning electron micrograph image of a PET post-PD exposure showing typical surface damage 


\subsubsection{Experimental set-up for PD-lifetime test}

Single sheets of the annealed samples with different additives were subjected to a $50 \mathrm{~Hz} \mathrm{AC}$ high voltage of $3 \mathrm{kV}$ until the sample breakdown due to PD erosion. This time to breakdown defines the lifetime. For each sample category, at least five samples were tested and the average values of the PD lifetime of each category were calculated.

\subsection{Sample characterisation}

\subsubsection{ATR-FTIR analysis}

Attenuated total reflection, Fourier transform infra-red (ATR-FTIR) spectra of samples in this project were collected using a Agilent 5500 Series ATR-FTIR instrument equipped with a single reflection diamond. The spectral range of the instrument is $650-4700 \mathrm{~cm}^{-1}$, with a resolution of $8 \mathrm{~cm}^{-1}$. 128 background and sample scans were accumulated for each spectrum. For each sample, five spectra were collected and then averaged using Panorama Pro® software from LabCognition GmbH (https://www.labcognition.com/en/Panorama.html). The ATR-IR technique is surface-biased, measuring changes only within $\sim 5 \mu \mathrm{m}$ of the surface.

\subsubsection{DSC analysis}

Differential scanning calorimetry (DSC) analyses were carried out using a TA instruments Q1000 DSC. The samples were weighed by using a Mettler Toledo XS105 balance with a readability level of $0.01 \mathrm{mg}$ and encapsulated in simple aluminium pans for which the instrument had been calibrated. An empty pan was selected as a reference. Samples, 2 mg, were punched from the PET films. A single-step heating programme with a heating rate of $10^{\circ} \mathrm{C} / \mathrm{min}$ was carried out in the temperature range between $30^{\circ} \mathrm{C}$ and $320^{\circ} \mathrm{C}$ for all samples in order to investigate the morphology of the samples. $\mathrm{N}_{2}$ was used as purge gas with a flow rate of $40 \mathrm{~mL} \mathrm{~min}^{-1}$.

\subsubsection{Surface profilometry}

The erosion depths of treated samples were measured using a Veeco Dektak 6M stylus profilometer. The profilometer is equipped with a diamond stylus with a radius of $12.5 \mu \mathrm{m}$. During each measurement, the stylus moves radially across the sample surface and the vertical motion of the stylus is measured. The starting point of the stylus for each scan was 
selected as the centre of the sample. The scan length and scan speed were set to $7000 \mu \mathrm{m}$ and $100 \mu \mathrm{m} \mathrm{s}^{-1}$, respectively. The erosion depth is defined as the height difference, along the stylus path, between the lowest point at the erosion valley and the highest point at the unexposed area.

\section{$3 \quad$ Results and discussion}

\subsection{DSC analysis}

Both as-received PET films are crystalline, with a single melt endotherm. The annealed samples all show a secondary endotherm, some $10-20^{\circ} \mathrm{C}$ above the annealing temperature [Figure 4]. The DSC multiple melting behaviour of PET and other polymers is widely discussed in the literature [12-31] and the interpretation has been contentious, with historically two schools of thought. The first was that there are two (or more) distinct populations of lamellae [12-14] and the second that there occurs upon heating in the DSC a complicated combination of offset endotherms (melting) and endotherms (recrystallization) of which only the net sum is detectable [15,16]. For PET, there can be as many as three endotherms, depending on crystallisation time, temperature and DSC scan rate. Consequently it is accepted that a combination of both explanations and a combination of experimental techniques is required to explain the observed melting behaviour.

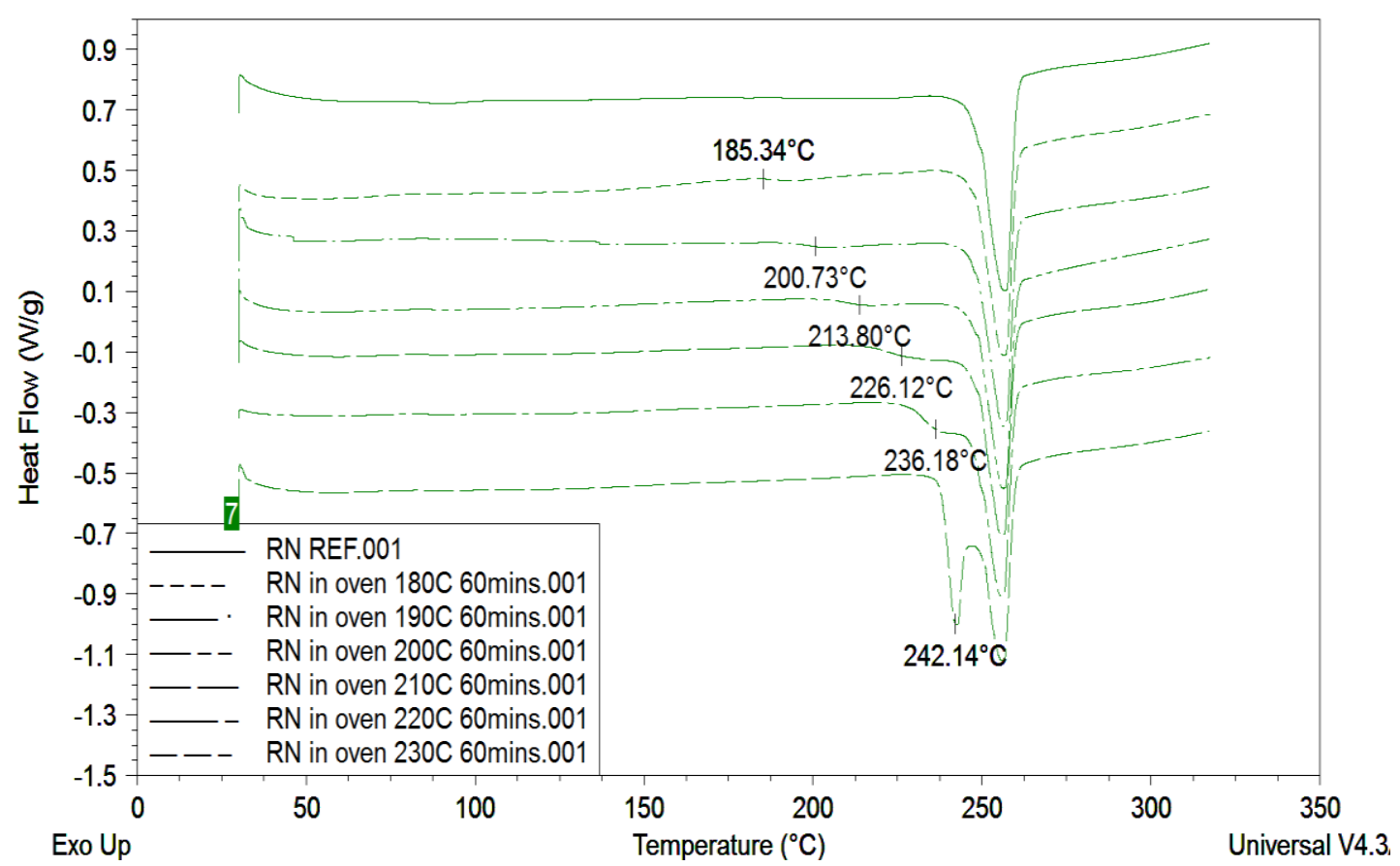

Figure 4: DSC analyses of the melting of PET after annealing at different temperatures 
Zhou and Clough [17] were the first to report three DSC endotherms and ascribed them to (in order of increasing temperature) to (i) the melting of secondary crystals, (ii) the melting of primary crystals and (iii) the melting of those crystals formed by a melting/recrystallization reorganisation during the DSC heating scan. Kong and Hay observed between one and three endotherms depending on crystallisation conditions. For samples crystallised from the melt for 2 hours at 125 and $150^{\circ} \mathrm{C}$ there were two endotherms, three for a $175^{\circ} \mathrm{C}$ crystallised sample and just one for a $225^{\circ} \mathrm{C}$ crystallisation. Consistent with nucleation control, for crystallisation temperatures of $200^{\circ} \mathrm{C}$ and below, the peak of the lowest melt endotherm increased linearly with crystallisation temperature indicating that the lamellar thickness increased with crystallisation temperature [18]. The endotherm increased in temperature with increasing crystallisation time and was thus ascribed to the melting of secondary lamellae formed by the crystallisation over extended periods of time of amorphous material between primary lamellae. Endotherm two was identified with the melting of the primary lamellae and endotherm 3 (which in temperature actually corresponds our highest temperature endotherm in the DSC scans) to thickened primary lamellae. Their interpretation was aided by studies undertaken using modulated temperature DSC (MDSC), which separates reversing and nonreversing heat flows, that reorganisation does indeed occur during the DSC heating scan. The number of observed endotherms was dependent on a balance of primary and secondary crystallisation, lamellar thickness distributions and the extent of reorganisation during melting. Using MDSC and time-resolved small-angle X-ray scattering, Wang et al. came to a similar conclusion with evidence for thinner lamellar stacks formed between primary stacks. There remains, however, some debate on the nature of the secondary crystals. For example, Medellín-Rodríguez et al favour subsidiary branched lamellae [20, 21] rather than secondary lamellar stacks.

Although our scenario is rather different, in that we are annealing pre-crystallised PET rather than developing secondary crystallites upon extended crystallisation from the melt, the interpretation is effectively identical, complicated only in that for commercial samples such as these used herein, the original crystallisation conditions are unknown. However, the DSC behaviour reported by Groeninckx and Raynaers who post-annealed PET crystallised at $100^{\circ} \mathrm{C}$ at temperatures ranging from $150-245^{\circ} \mathrm{C}$ [22] is similar to that described above. Two melt endotherms were observed with the lower melt endotherm peak temperature increased with increasing annealing temperature. The exception was at the highest crystallisation temperatures where a single endotherm was noted, similar to that observed by Kong and Hay [18]. In keeping with most interpretations, they assigned the lower temperature 
endotherm to that of crystallites that developed upon annealing (effectively a secondary crystallisation process), and the higher temperature endotherm to that of the morphology consequent upon reorganisation during the DSC scan.

Groeninckx and Raynaers were not dogmatic about the nature of the crystal perfection that leads to higher melt temperatures from higher annealing temperatures, and indeed the Gibbs-Thomson equation (equation 1) is agnostic as to whether the increased stability is due to fold-surface smoothing, internal perfection or lamellar thickening.

Of course, annealing at elevated temperatures for extended periods of time can induce more than simply physical changes. We have demonstrated that annealing PET at $190^{\circ} \mathrm{C}$ for 4 hours even in dry nitrogen can induce chain scission [23]. Flores et al report that the mechanical properties (specifically hardness) of annealed PET tend to decrease with increasing annealing temperature in the range $190-240^{\circ} \mathrm{C}$, albeit for annealing times of 9 hours [24]. Nevertheless, any reduction in molecular weight would reduce the number of entanglements in the amorphous regions and the number of inter-lamellar tie molecules $[21,24]$ and this can affect subsequent crystallisation and melting behaviour $[21,25]$.

Overall, therefore, the DSC data from our samples is consistent with the literature. There is a population of primary lamellae created by the initial filming process that remains unchanged by the annealing process and melts with a peak temperature of $256-257^{\circ} \mathrm{C}$ (unfilled) or $245-246^{\circ} \mathrm{C}$ (filled)and ( $T_{m}$ is effectively constant, Table 1 and Table SM1). In addition, upon annealing there develops a population of secondary lamellae of increased thickness at higher annealing temperatures, as shown by the increasing temperature of the lower temperature endotherm, $\mathrm{T}_{\mathrm{m}(1)}$ (figure 4). 


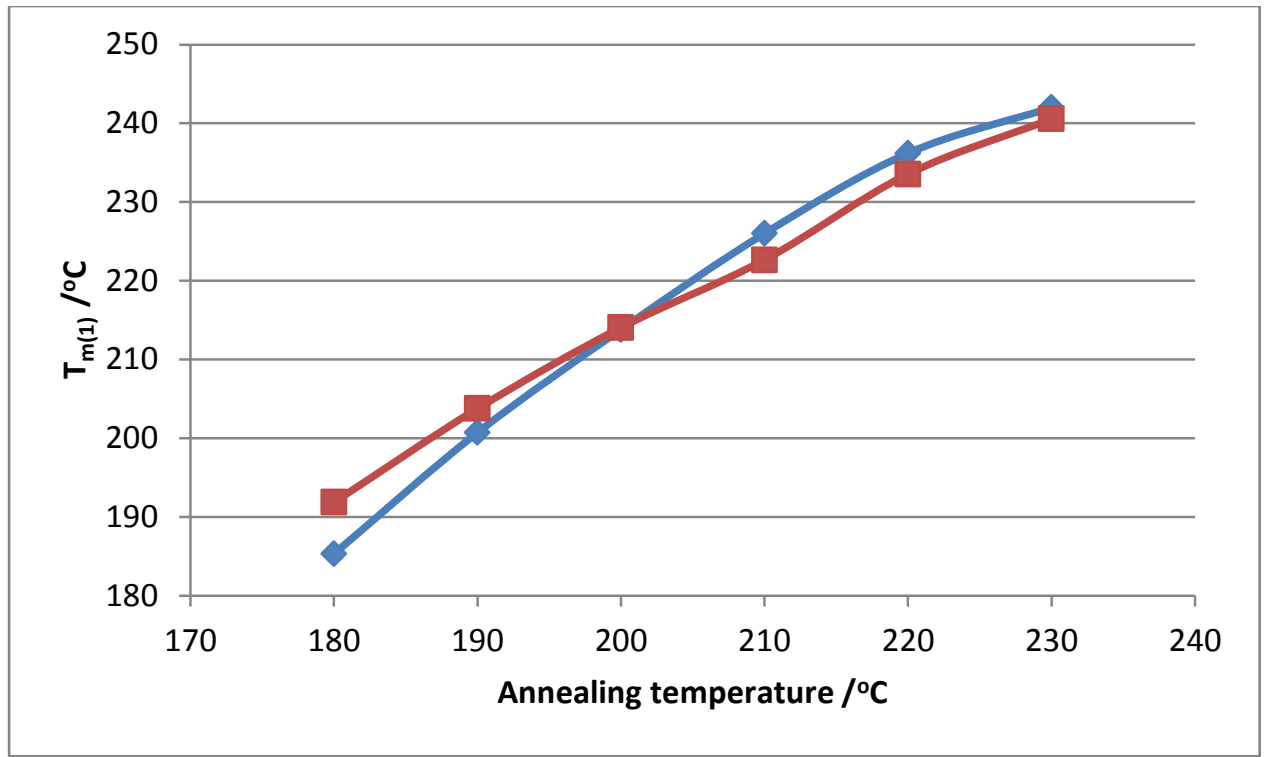

Figure 5: Endotherm peak 1 temperature, $\mathrm{T}_{\mathrm{m}(1)}$, as a function of annealing temperature for unfilled (diamonds) and filled (square) PET.

It is interesting to note that the filled PET behaves rather differently at the highest annealing temperature. The low temperature endotherm (peak $241^{\circ} \mathrm{C}$ ) dominates the higher temperature endotherm, reducing it to a shoulder to higher temperature $\left(245^{\circ} \mathrm{C}\right)$. Something of this sort has been seen by Kong and Hay and Groeninckx and Raynaers. Kong and Hay use this to argue that the higher temperature peak is associated with the melting of lamellae (both secondary and primary) reorganising during the scan, the high stability of the secondary lamellae inhibiting the reorganisation of the primary lamellae. Baldenegro-Perez et al. propose a model for how the morphology is affected by annealing at different temperatures that suggests a step-change in morphology around $210-220^{\circ} \mathrm{C}$ [25], Figure 6. 


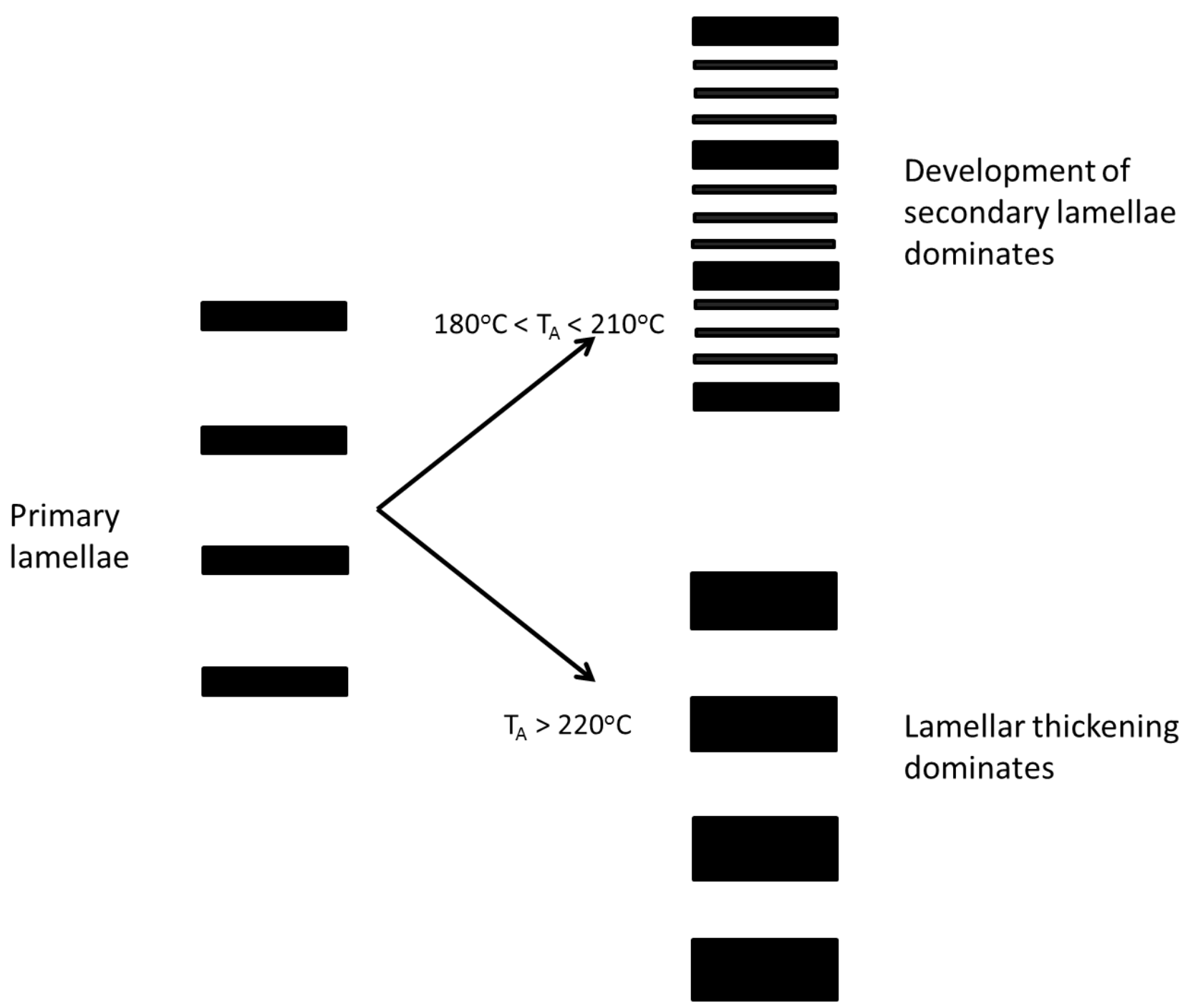

Figure 6: Development of lamellae for PET annealed at various temperatures. From [25]

Di Lorenzo et al. also found a discontinuity in the crystallisation behaviour of PET at $215^{\circ} \mathrm{C}$. $[26,27]$. This they ascribed to a restriction in chain mobility in the vicinity of lamellae, due to fold entanglements and tie molecules, which leads effectively to a vitrification of the amorphous phase. At lower annealing temperatures, this constraint limits lamellar reorganisation. However, at higher annealing temperatures above some critical temperature, believed to be $210^{\circ} \mathrm{C}$, these regions de-vitrify and the relaxation of the previously constrained molecules facilitates lamellar thickening and perfection via the annihilation of defects inside the lamellae or at the interfaces of the crystalline regions. Interestingly, whilst Di Lorenzo et al. invoke the concept of what they call a rigid amorphous fraction, similar behaviour would result from chain scission, as noted earlier. Whilst the exact processing conditions for our commercial films are unknown, the heat-set (crystallisation temperature) is likely to have been in the order of $200^{\circ} \mathrm{C}$, and it is thus possible to argue that whilst the 
original population of lamellae would not be affected by annealing below this temperature, they would be open to reorganisation above this temperature.

In order to further investigate the development of the lamellar thickness during our annealing treatment, a peak fitting process was applied to the melting doublets of each sample following the model of Ribes-Graus et al. [28, 29]. The deconvolution processes were performed by the OriginPro 8.6 software and Gaussian-Lorentzian cross was selected as the peak type for the processes. Melting calorimetric parameters such as melting points $T_{m}{ }^{n}$, lamellae thickness $I_{c}{ }^{n}$, and overall crystallinity degree $X_{c}(\%)$ are summarized in table 1 . The lamellae thicknesses $I_{c}{ }^{n}$ were calculated using the Gibbs-Thomson equation [equation 1].

$$
l_{c}\left(T_{m}\right)=\left[\left(1-\frac{T_{m}}{T_{m}^{0}}\right) \cdot \frac{\Delta h_{m v}}{2 \sigma_{e}}\right]^{-1}
$$

where $T_{m}$ is the melting temperature, $T_{m}{ }^{\circ}\left(291^{\circ} \mathrm{C}\right)$ is the melting temperature of infinitely thick PET lamellae (equilibrium melting temperature), $\sigma_{\mathrm{e}}\left(0.106 \mathrm{~J} \mathrm{~m}^{-2}\right)$ is the fold surface free energy, $\Delta \mathrm{h}_{\mathrm{mv}}\left(2.1 \times 10^{8} \mathrm{~J} \mathrm{~m}^{-3}\right)$ is the melting enthalpy per volume unit [30]. The degree of crystallinity $\mathrm{X}_{\mathrm{c}}$ was calculated by using equation 2 :

$$
X_{C}=\frac{\Delta H_{m}}{\Delta H_{100 \%}}
$$

where $\Delta \mathrm{H}_{\mathrm{m}}$ is the measured melting enthalpy of the sample and $\Delta \mathrm{H}_{100 \%}$ is the melting enthalpy of a $100 \%$ crystalline PET, which is $140 \mathrm{~J} \mathrm{~g}^{-1}$ [30]. The thicknesses of lamellae formed upon annealing, $\mathrm{I}_{\mathrm{c}}{ }^{1}$, and the original population, $\mathrm{I}_{\mathrm{c}}{ }^{2}$, for PET annealed at different temperatures, calculated from Equation 1, are also shown in Figure 7. Corresponding DSC data and analysed plots of PET-BaSO - UV can be found in figures SM1 and SM2 and table SM1 of the Supplementary Material. Of particular interest here, of course, is the population of the lower melting lamellae as these are the lamellae formed during the annealing process and thus which alter the PD behaviour. As expected, lamellae formed at higher annealing temperatures are noticeably thicker than those formed at lower temperatures, whilst the original population of lamellae formed by the original filming process (whether they are regarded or not as reorganising during the scan) are effectively constant in thickness at the point of melting in all samples, annealed or not. 


\begin{tabular}{|c|c|c|c|c|c|c|}
\hline Annealing & $\mathrm{T}_{\mathrm{m}}{ }^{1}\left({ }^{\circ} \mathrm{C}\right)$ & $\mathrm{L}_{\mathrm{c}}{ }^{1}(\AA)$ & $\mathrm{T}_{\mathrm{m}}{ }^{2}\left({ }^{\circ} \mathrm{C}\right)$ & $\mathrm{L}_{\mathrm{c}}{ }^{2}(\AA)$ & $\Delta \mathrm{H}_{\mathrm{m}}\left(\mathrm{J} \mathrm{g}^{-1}\right)$ & $\mathrm{X}_{\mathrm{c}}$ \\
& & & & & & \\
\hline As supplied & $\mathrm{N} / \mathrm{A}$ & $\mathrm{N} / \mathrm{A}$ & $257.0 \pm 0.2$ & 168.4 & 47.17 & 0.34 \\
\hline 180 & $185.3 \pm 1.2$ & 54.0 & $256.8 \pm 0.3$ & 167.4 & 48.45 & 0.35 \\
\hline 190 & $200.7 \pm 1.1$ & 63.2 & $256.8 \pm 0.2$ & 167.4 & 51.08 & 0.36 \\
\hline 200 & $213.8 \pm 0.8$ & 74.0 & $256.6 \pm 0.4$ & 166.7 & 51.20 & 0.37 \\
\hline 210 & $226.1 \pm 2.4$ & 88.0 & $256.2 \pm 0.2$ & 164.6 & 53.70 & 0.38 \\
\hline 220 & $236.2 \pm 1.7$ & 104.1 & $256.1 \pm 0.4$ & 164.6 & 54.22 & 0.39 \\
\hline 230 & $242.1 \pm 1.5$ & 116.9 & $256.2 \pm 0.2$ & 164.6 & 57.83 & 0.41 \\
\hline
\end{tabular}

Table 1: Morphology data for PET annealed for 60 mins at various temperatures from 180 to $230^{\circ} \mathrm{C}$ 


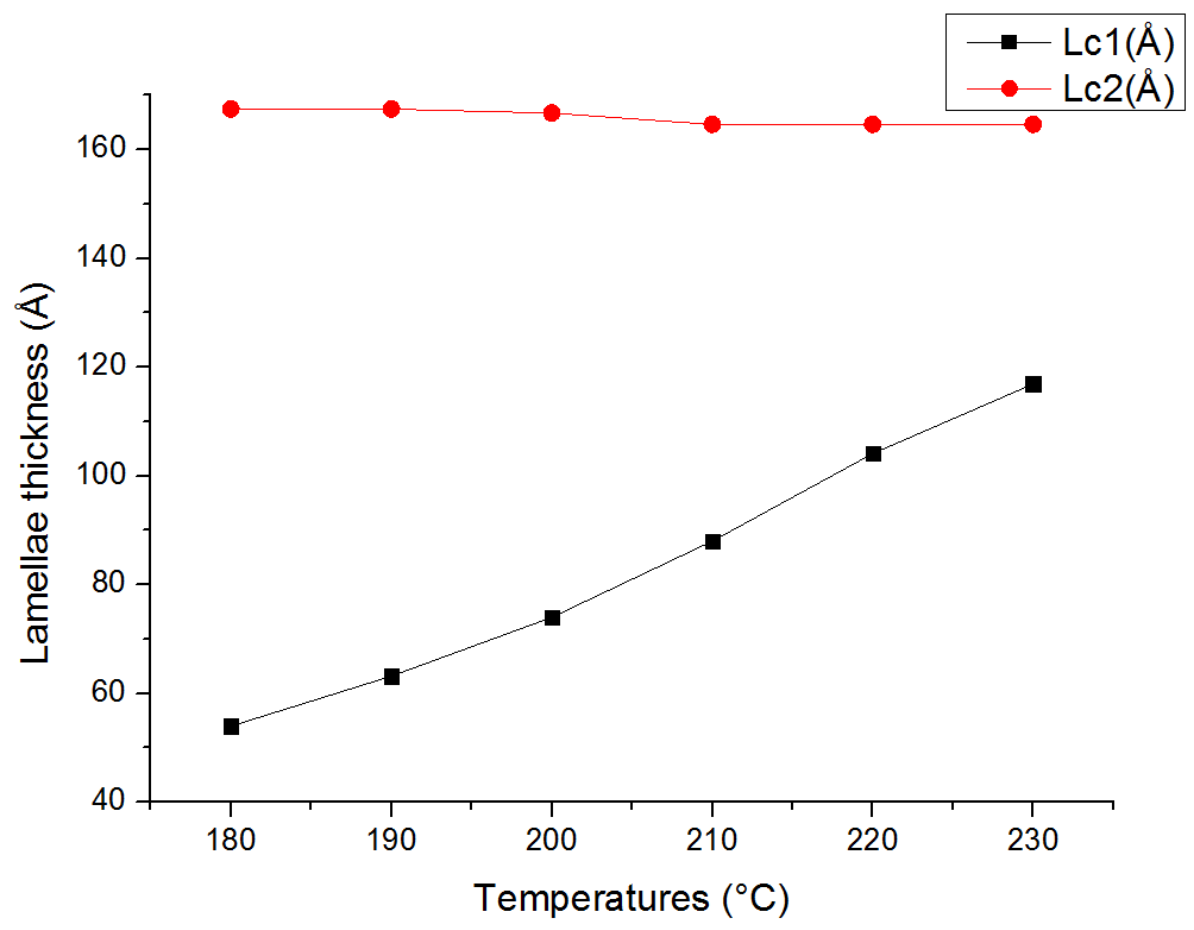

Figure 7: Thicknesses of lamellae formed upon annealing, $L_{c}{ }^{1}$, and the original population, $\mathrm{L}_{c}{ }^{2}$, of PET annealed for 60 mins at various temperatures from 180 to $230^{\circ} \mathrm{C}$

\subsection{FTIR analysis}

FTIR is a useful tool to analyse PET morphology and degree of crystallinity, which can be achieved by measuring the ratio of absorption peaks at 1473 and $1455 \mathrm{~cm}^{-1}$ that are attributed to the bending of the glycol $\mathrm{CH}_{2}$ in crystalline and amorphous phases, respectively $[28,32,33]$. OriginPro 8.6 software was utilised in this project for deconvolution of FTIR data to study the development of the crystalline portion of PET quantitatively. The peak types were selected as 'Gaussian' and the peak centres of two peaks were fixed to 1473 and 1455 $\mathrm{cm}^{-1}$. The comparison of the doublets during the isothermal annealing is shown in Figure 8, one can see that after annealing treatment the peak at $1473 \mathrm{~cm}^{-1}$ increased while the peak at $1455 \mathrm{~cm}^{-1}$ decreased, suggesting the development of the crystalline portion of PET. These two peaks have been widely used to characterize the surface morphology of samples in the literature [28, 31, 34-36] and the crystallinity degree of sample surface can be calculated using the following equation:

$$
X_{c}=\frac{A_{c}}{A_{c}+A_{a}}
$$


The results for PET are shown in table 2 (FTIR data for PET-BaSO - UV are given in Supplementary Material, Table SM2). It is seen that the data trends of the sample crystalline content, $\mathrm{X}_{\mathrm{c}}$, in tables 1 and 2 are highly consistent although the values obtained by DSC are a little larger than the data by FTIR, potentially reflecting the difference between surface and bulk crystallinity values but also the difficulty in using DSC to determine crystalline content, given that the sample can undergo melting and recrystallization during the heating scan.

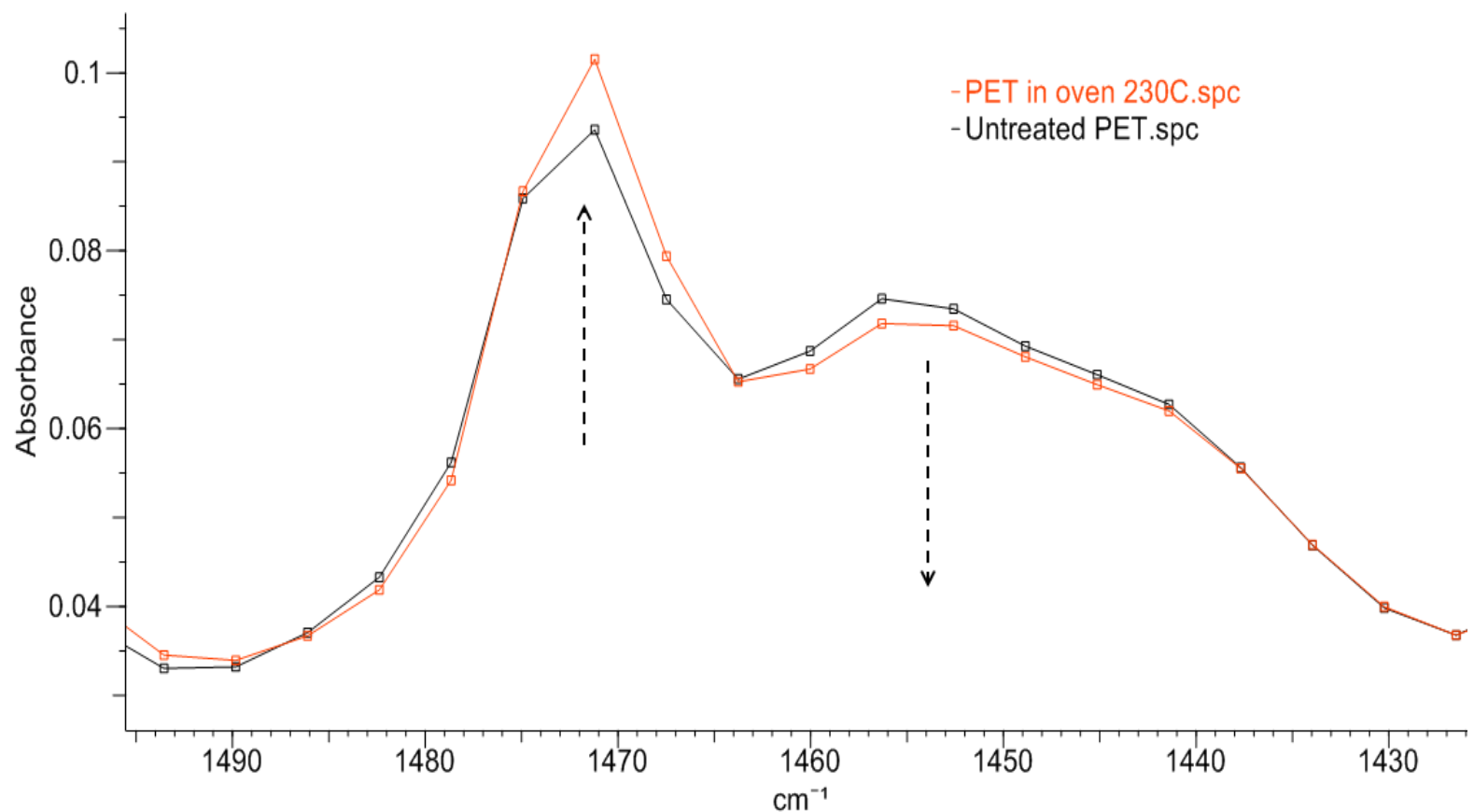

Figure 8: Overlaid 1430-1500 $\mathrm{cm}^{-1}$ regions of ATR-FTIR spectra of PET untreated and annealed at $230^{\circ} \mathrm{C}$ 


\begin{tabular}{|c|c|c|c|}
\hline Sample & $\begin{array}{c}\mathrm{A}\left(1455 \mathrm{~cm}^{-1}\right) \\
\text { / arbitrary units }\end{array}$ & $\begin{array}{c}\mathrm{A}\left(1473 \mathrm{~cm}^{-1}\right) \\
\text { / arbitrary units }\end{array}$ & $\mathrm{X}_{\mathrm{c}} / \%$ \\
\hline Untreated PET & 70.3 & 29.7 & 29.7 \\
\hline $180^{\circ} \mathrm{C}$ & 69.7 & 30.3 & 30.3 \\
\hline $190^{\circ} \mathrm{C}$ & 69.7 & 30.3 & 30.3 \\
\hline $200^{\circ} \mathrm{C}$ & 69.4 & 30.6 & 30.9 \\
\hline $210^{\circ} \mathrm{C}$ & 69.1 & 30.9 & 31.7 \\
\hline $220^{\circ} \mathrm{C}$ & 68.3 & 31.7 & 32.6 \\
\hline $230^{\circ} \mathrm{C}$ & 67.4 & 32.6 & \\
\hline
\end{tabular}

Table 2: Crystallinity degrees of untreated and annealed PET determined by ATR-FTIR

\subsection{Surface profilometry and PD lifetime analysis}

\subsubsection{Surface profilometry}

PD tests were carried out for the two different annealed samples, namely PET, PET-BaSO ${ }_{4}^{-}$ UV by using the PD experimental set-up shown in figure 1. After PD exposure, samples on the top layer (the annealed one) of each stack were removed for erosion depth tests. The erosion depths of the samples are plotted in figure 9. It can be clearly seen that the erosion depths in general decreased with the increase of annealing temperatures for each type of sample. To be more specific, the erosion depths of the samples decreased by only a relatively small amount when the annealing temperatures are lower than $210^{\circ} \mathrm{C}$ but when the annealing temperatures are higher than $210^{\circ} \mathrm{C}$, a sharp decrease of PD erosion depths could be found for all both samples. The consistently lower level of erosion across the PET$\mathrm{BaSO}_{4}$-UV film reflects the filler 'pile-up' and UV stabilising effect of the Tinuvin additive [8]. 


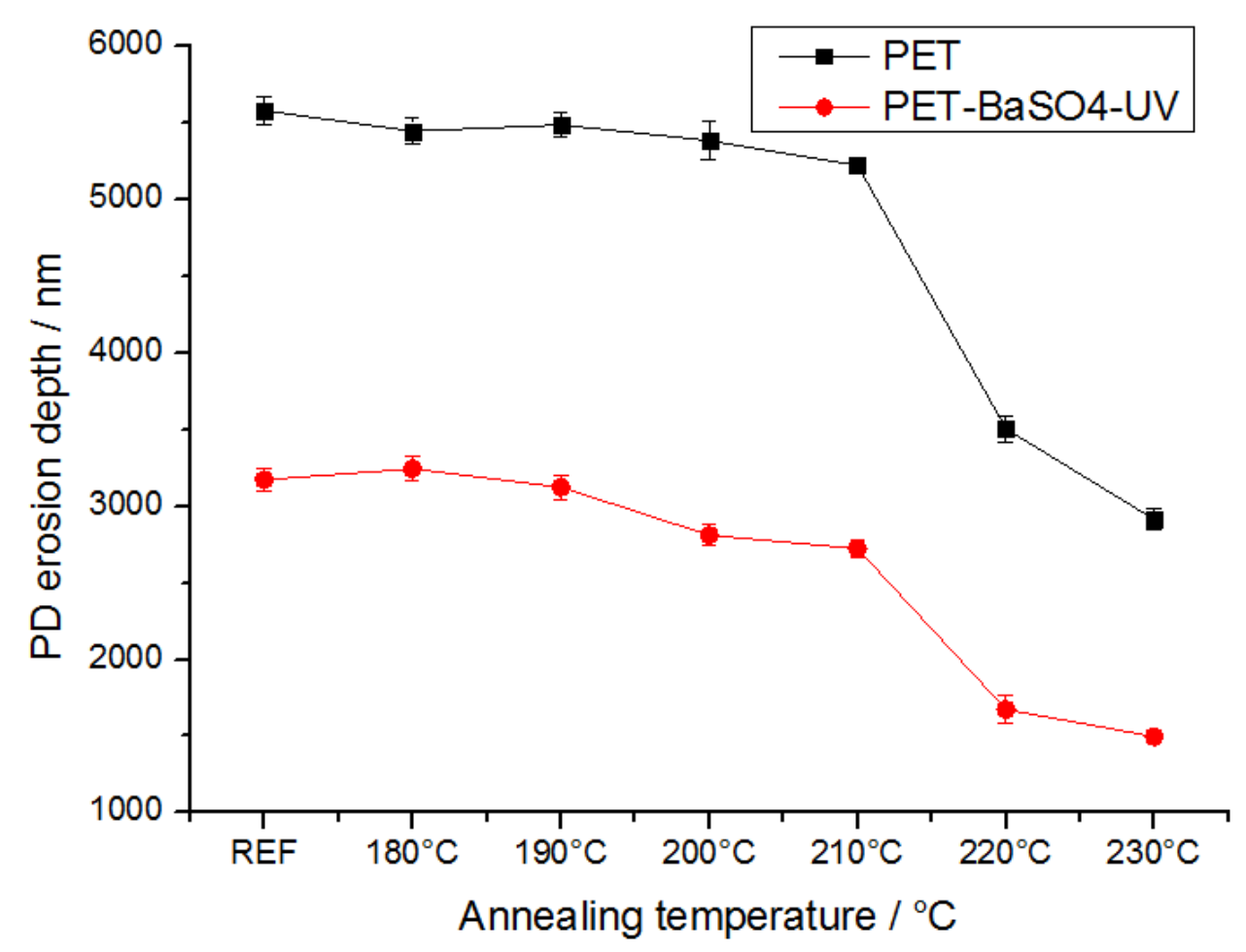

Figure 9: PD erosion depths of samples after annealing at different temperatures

\subsubsection{PD lifetime analysis}

PD lifetime tests were also carried out for all the annealed samples as described in section 2.3.2 and the results are illustrated in figure 10. It is logical to expect that the PD lifetime is directly proportional to PD resistance for the same type of polymeric materials. Therefore, it is no surprise that the PD lifetimes of the annealed samples are enhanced greatly when the annealing temperatures are higher than $210^{\circ} \mathrm{C}$, as shown in figure 7 . As with the erosion depths, we again see the superior stability of the filled and UV stabilised system. 


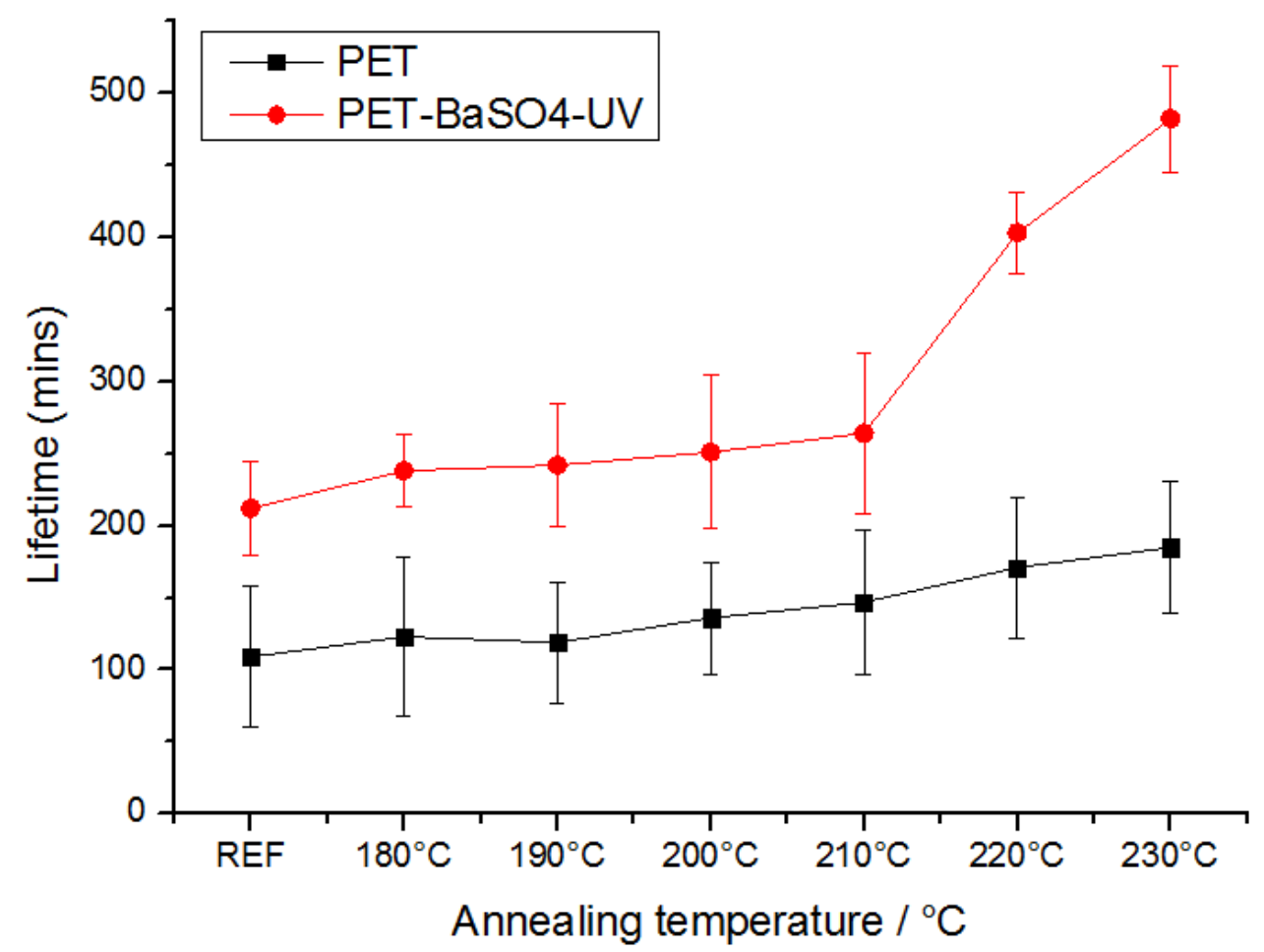

Figure 10: PD lifetimes of samples after annealing at different temperatures

\section{Conclusions}

Polymeric films with thicker lamellae and higher crystallinity are expected to possess a better PD resistance [9, 10]. Microvoids, in addition to the free volume, are inevitable in polymers, particularly below $T_{g}$, and they usually appear in the amorphous regions of the materials. The permittivity of the crystalline regions is higher than that of the amorphous regions, making electrical discharge concentrate more on the crystalline regions. Higher levels of crystallinity and thicker and more perfect lamellae will provide a better PD-resisting ability than the thinner, less perfect, lamellae.

From our FTIR data, the degree of crystallinity in our samples increases upon annealing and the DSC data, consistent with the literature, show the presence of a population of secondary lamellae, increasingly thicker and more perfect lamellae as the annealing temperature increases. It is these secondary lamellae that develop upon the annealing treatment that influence the PD behaviour.

PD and breakdown tests were carried out for the untreated and annealed PET. It was found that regardless of the PET film type (filled or unfilled) both PD resistances and PD lifetimes of the annealed samples were superior to that of the untreated samples, especially when the 
annealing temperature $T_{c}$ is above $210^{\circ} \mathrm{C}$. Significant improvements of the sample PD resistances are observed in the high annealing temperature region, as shown in figure 9. Similarly, from figure 10, remarkable increases of the sample PD lifetimes can be achieved when the annealing temperature is higher than $210^{\circ} \mathrm{C}$. PD lifetimes can be at least extended by a factor of $70 \%$ when the samples were annealed at their highest annealing temperatures. However, it should be noted that when the annealing temperature is in the region of medium temperature $\left(180^{\circ} \mathrm{C}<\mathrm{T}_{\mathrm{c}}<210^{\circ} \mathrm{C}\right)$, only modest increases of $\mathrm{PD}$ lifetimes can be found for the samples. The origin of the marked improvement in $\mathrm{PD}$ behaviour at $210^{\circ} \mathrm{C}$ is unclear from our data alone. FTIR data does show a faster rate of increase in degree of crystallinity above $210^{\circ} \mathrm{C}$ but the effect is relatively small. However, it is unlikely to be coincidental that the improvement occurs in the temperature regime where the literature suggests a transition in morphological behaviour [18, 22, 26, 27]. On this basis, schematics of electrical tree propagations caused by PD in untreated and annealed PET films are shown in Figure 11. It is known that PD will selectively propagate through the 'weak points', namely the amorphous parts of the materials. If the lamellae are thin and defective they can block the electrical tree propagation paths to a certain extent but the electrical trees are believed to be able to penetrate through the defective lamellae (Figure 11 (b)). As the annealing temperatures increase and the lamellae become more perfect, their resistance increases.

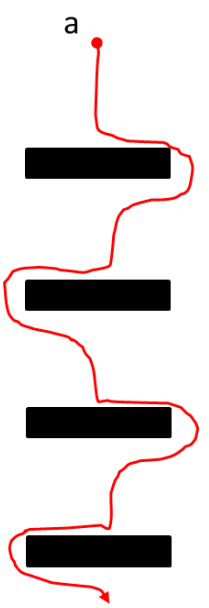

Non-annealed

Primary lamellae

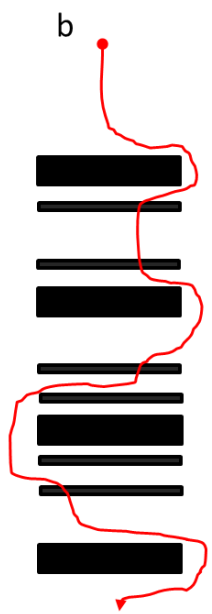

$180^{\circ} \mathrm{C}<\mathrm{T}_{\mathrm{A}}<220^{\circ} \mathrm{C}$

Development of secondary lamellae dominates

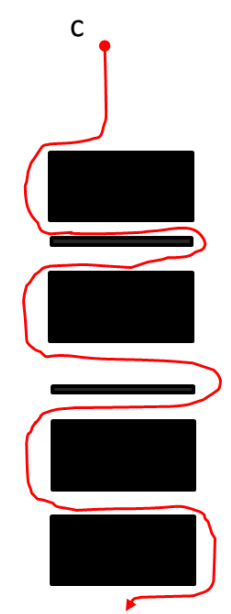

$\mathrm{T}_{\mathrm{A}}>220^{\circ} \mathrm{C}$

Lamellar thickening dominates

Figure 11: Propagation of PD-initiated electrical trees in (a) non-annealed PET (b) PET annealed at $\mathrm{T}_{\mathrm{A}}<220^{\circ} \mathrm{C}$ (c) PET annealed at $\mathrm{T}_{\mathrm{A}}>220^{\circ} \mathrm{C}$ 
6. Acknowledgements

RT thanks the University of Strathclyde for provision of a University Scholarship. 


\section{$5 \quad$ References}

[1] Phillips, N.H., Givot, B., O'Brien, B., Korba, G. and Loyd, J., 2012, June. Analytical techniques used to determine chemical degradation of polymeric materials used in PV modules after sustained exposure to partial discharge voltages. In Photovoltaic Specialists Conference (PVSC), 2012 38th IEEE (pp. 000714-000719). IEEE.

[2] Kuffel, J. and Kuffel, P., 2000. High voltage engineering fundamentals. Newnes.

[3] Tanaka, T. and lizuka, T., 2010, October. Generic PD resistance characteristics of polymer nanocomposites. In Electrical Insulation and Dielectric Phenomena (CEIDP), 2010 Annual Report Conference on (pp. 1-4). IEEE.

[4] O'Hare, L.A., Smith, J.A., Leadley, S.R., Parbhoo, B., Goodwin, A.J. and Watts, J.F., 2002. Surface physico-chemistry of corona-discharge-treated poly(ethylene terephthalate) film. Surface and interface analysis, 33(7), pp617-625.

[5] Pandiyaraj, K.N., Selvarajan, V., Deshmukh, R.R. and Bousmina, M., 2008. The effect of glow discharge plasma on the surface properties of poly(ethylene terephthalate)(PET) film. Surface and Coatings Technology, 202(17), pp4218-4226.

[6] Ding, L., Shao, L. and Bai, Y., 2014. Deciphering the mechanism of corona discharge treatment of BOPET film. RSC Advances, 4(42), pp21782-21787.

[7] Vitellas, I., Theodosiou, K., Gialas, I. and Agoris, D.P., 2005. Mechanism of degradation and breakdown in PET films under high intensity AC fields. The European Physical Journal Applied Physics, 30(2), pp83-89.

[8] Tang, R., Liggat, J.J., and Siew, W.H., 2018. Filler and additive effects on partial discharge degradation of PET films used in PV devices, Polymer Degradation and Stability, 150, pp148-157

[9] Ikeda, I., 2013. Factors determining the partial discharge resistance of polymers, IEEJ Transactions on Fundamentals and Materials, 133(3), pp75-80. 
[10] Ohki, Y. and Miyata, K., 2010. Effects of temperature and crystallinity on partial discharge resistance of poly-L-lactic acid, IEEJ Transactions on Electrical and Electronic Engineering, 5(3), pp323-327.

[11] Natu, A.A., Lofgren, E.A. and Jabarin, S.A., 2005. Effect of morphology on barrier properties of poly(ethylene terephthalate). Polymer Engineering \& Science, 45(3), pp400409.

[12] Chung, J.S. and Cebe, P. 1992. Melting behaviour of poly (phenylene sulphide): 1. Single stage melt crystallization, Polymer, 33, pp2312-2324.

[13] Chung, J.S. and Cebe, P., 1992, Melting behaviour of poly (phenylene sulphide): 2. Multiple stage melt crystallization, Polymer, 33 (11), pp2325 - 2333.

[14] Holdsworth, P.J. and Turner-Jones, A. 1971 The melting behaviour of heat crystallised pol(ethylene terephthalate), Polymer, 12(3), pp195-208.

[15] Blundell, D.J., 1987 On the interpretation of multiple melting peaks in poly(ether ether ketone) Polymer, 28(13), pp2248-2251.

[16] Basset, D.C., Olley, R.H. and AI Raheil, I.A.M., 1988. On crystallisation phenomena in PEEK, Polymer, 29(10), pp1745-1754.

[17] Zhou, C. and Clough, R.S, 1988, Multiple melting endotherms of poly(ethylene terephthalate) Polymer Engineering and Science 28(2), pp65-68.

[18] Kong, Y. and Hay, J.N., 2003. Multiple melting behaviour of poly(ethylene terephthalate). Polymer, 44(3), pp623-633.

[19] Wang, Z.G., Hsiao, B.S., Sauer, B.B. and Kampert, W.G., 1999. The nature of secondary crystallization in poly (ethylene terephthalate). Polymer, 40(16), pp.4615-4627.

[20] Medellín-Rodríguez, F.J. , Phillips, P.J. and Lin, J.S., 1996, Melting behavior of hightemperature polymers, Macromolecules 29(3) pp7491-7501. 
[21] Medellin-Rodriguez, F.J., Phillips, P.J., Lin, J.S. and Campos, R., 1997. The triple melting behavior of poly(ethylene terephthalate): Molecular weight effects. Journal of Polymer Science Part B: Polymer Physics, 35(11), pp1757-1774.

[22] Groeninckx, G. and Raynaers, H., 1980, Morphology and melting behaviour of semicrystalline poly(ethylene terephthalate) II: Annealed PET, Journal of Polymer Science, Polymer Physics Edition, 18, pp1325-1341.

[23] Liggat, J.J., and Turnbull, L. Ageing of poly(ethylene terephthalate) and poly(ethylene naphthalate) under moderately accelerated conditions, Journal of Applied Polymer Science, 124(6), pp4517-4529.

[24] Flores, A., Pieruccini, M., Stribeck, N., Funari., S.S., Bosch, E. and Balta-Calleja, F.J., 2005, Structure formation in poly(ethylene terephthalate) upon annealing as revealed by microindentation hardness and X-ray scattering. Polymer, 46, pp9404-9410.

[25] Baldenegro-Perez, L.A., Navarro-Rodriguez, D., Medellin-Rodriguez, F.J., Hsiao, B., Avila-Orta, C.A. and Sics, I., 2014. Molecular weight and crystallization temperature effects on poly(ethylene terephthalate) (PET) homopolymers, an isothermal crystallization analysis. Polymers, 6(2), pp583-600.

[26] Di Lorenzo, M.L., Righetti, M.C., Cocca, M. and Wunderlich, B., 2010. Coupling between crystal melting and rigid amorphous fraction mobilization in poly (ethylene terephthalate). Macromolecules, 43(18), pp7689-7694.

[27] Righetti, M.C., Laus, M. and Di Lorenzo, M.L., 2014. Rigid amorphous fraction and melting behavior of poly(ethylene terephthalate). Colloid and Polymer Science, 292(6), pp1365-1374.

[28] Badia, J.D., Strömberg, E., Karlsson, S. and Ribes-Greus, A., 2012. The role of crystalline, mobile amorphous and rigid amorphous fractions in the performance of recycled poly (ethylene terephthalate)(PET). Polymer Degradation and Stability, 97(1), pp98-107.

[29] Santonja-Blasco, L., Moriana, R., Badía, J,D., Ribes-Greus, A., 2010. Thermal analysis applied to the characterization of degradation in soil of polylactide: I. Calorimetric and viscoelastic analyses. Polymer Degradation and Stability 95 pp2185-2191. 
[30] Lu, X.F. and Hay J.N., 2001. Isothermal crystallization kinetics and melting behaviour of poly(ethylene terephthalate), Polymer, 42, pp9423-9431.

[31] Woo, E.M. and Ko, T.Y., 1996. A differential scanning calorimetry study on poly(ethylene terephthalate) isothermally crystallized at stepwise temperatures: multiple melting behavior re-investigated. Colloid and Polymer Science, 274(4), pp309-315.

[32] Rastogi, R., Vellinga, W.P., Rastogi, S., Schick, C. and Meijer, H.E.H., 2004. The threephase structure and mechanical properties of poly (ethylene terephthalate). Journal of Polymer Science Part B: Polymer Physics, 42(11), pp2092-2106.

[33] Kong, Y. and Hay, J.N., 2003. The enthalpy of fusion and degree of crystallinity of polymers as measured by DSC. European Polymer Journal, 39(8), pp1721-1727.

[34] Karagiannidis, P.G., Stergiou, A.C. and Karayannidis, G.P., 2008. Study of crystallinity and thermomechanical analysis of annealed poly(ethylene terephthalate) films. European Polymer Journal, 44(5), pp1475-1486.

[35] Cole, K.C., Ajji, A. and Pellerin, E., 2002. New insights into the development of ordered structure in poly(ethylene terephthalate). 1. Results from external reflection infrared spectroscopy. Macromolecules, 35(3), pp770-784.

[36] Atkinson, J.R., Biddlestone, F. and Hay, J.N., 2000. An investigation of glass formation and physical ageing in poly (ethylene terephthalate) by FT-IR spectroscopy. Polymer, 41(18), pp6965-6968. 


\section{Supplementary Information}

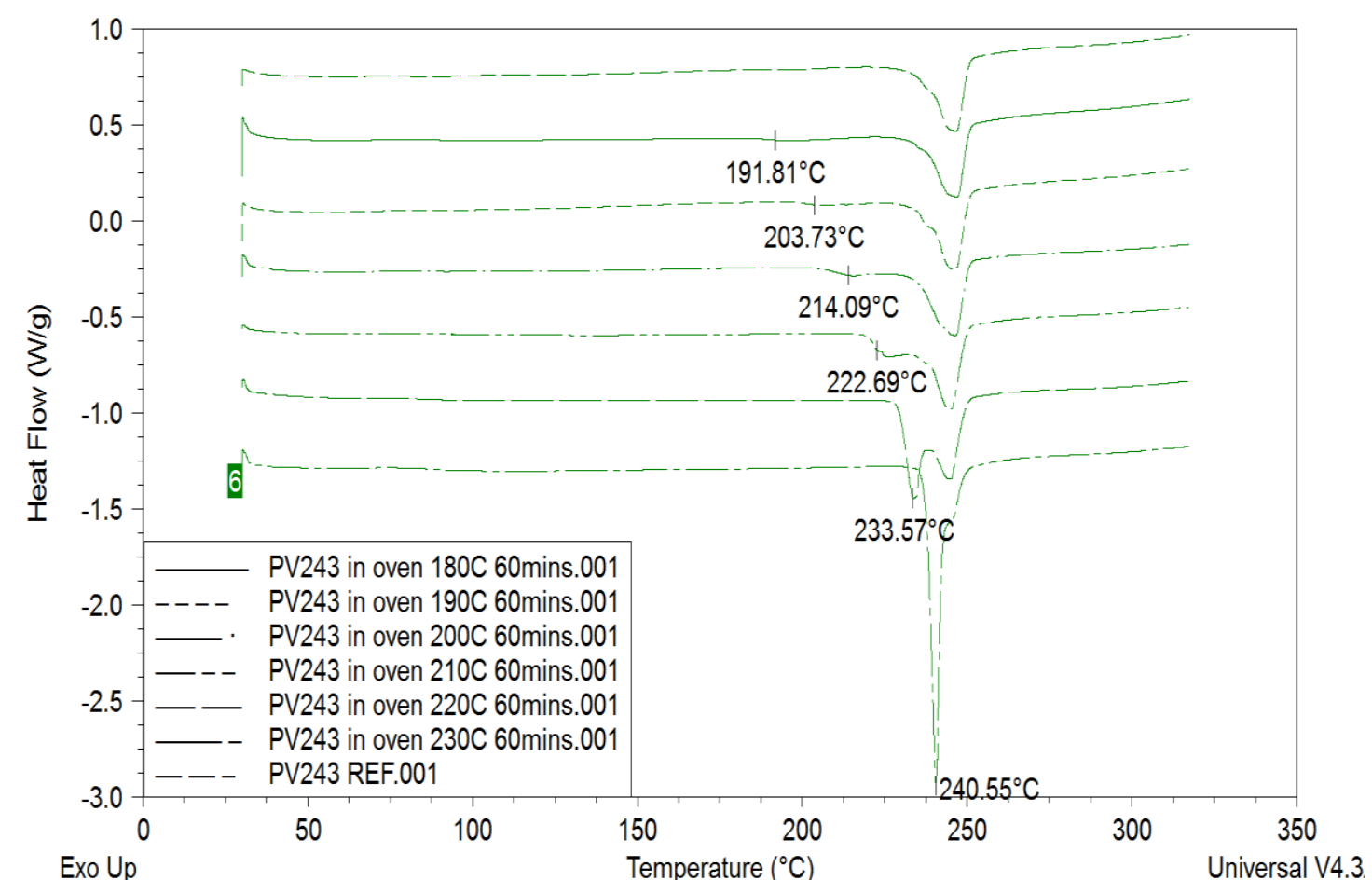

Figure SM1: DSC analyses of the melting of PET-BaSO ${ }_{4}-\mathrm{UV}$ after crystallization at different temperatures

\begin{tabular}{|c|c|c|c|c|c|c|}
\hline Samples & $\mathrm{T}_{\mathrm{m}}{ }^{1}(\mathrm{~K})$ & $\mathrm{L}_{\mathrm{c}}{ }^{1}(\AA)$ & $\mathrm{T}_{\mathrm{m}}{ }^{2}(\mathrm{~K})$ & $\mathrm{L}_{\mathrm{c}}{ }^{2}(\AA)$ & $\Delta \mathrm{H}_{\mathrm{m}}(\mathrm{J} / \mathrm{g})$ & $\mathrm{X}_{\mathrm{c}} \%$ \\
\hline $\mathrm{REF}$ & $\mathrm{N} / \mathrm{A}$ & $\mathrm{N} / \mathrm{A}$ & $246.6 \pm 0.4$ & 128.8 & 33.87 & 24.19 \\
\hline $180^{\circ} \mathrm{C}$ & $191.2 \pm 0.6$ & 57.5 & $246.8 \pm 0.3$ & 129.4 & 36.66 & 26.18 \\
\hline $190^{\circ} \mathrm{C}$ & $203.8 \pm 1.4$ & 65.4 & $246.3 \pm 0.4$ & 127.9 & 35.65 & 25.46 \\
\hline $200^{\circ} \mathrm{C}$ & $214.0 \pm 1.1$ & 74.1 & $246.4 \pm 0.4$ & 128.0 & 38.73 & 27.66 \\
\hline $210^{\circ} \mathrm{C}$ & $222.6 \pm 0.9$ & 83.5 & $246.4 \pm 0.2$ & 128.0 & 41.90 & 29.93 \\
\hline $220^{\circ} \mathrm{C}$ & $233.5 \pm 1.3$ & 99.4 & $245.0 \pm 0.4$ & 124.3 & 42.72 & 30.51 \\
\hline $230^{\circ} \mathrm{C}$ & $240.5 \pm 1.6$ & 113.2 & $245.0 \pm 0.3$ & 124.3 & 43.27 & 30.91 \\
\hline
\end{tabular}

Table SM1: Morphology data of PET-BaSO ${ }_{4}-\mathrm{UV}$ annealed at various temperatures from 180 to $230^{\circ} \mathrm{C}$ for 60 mins 


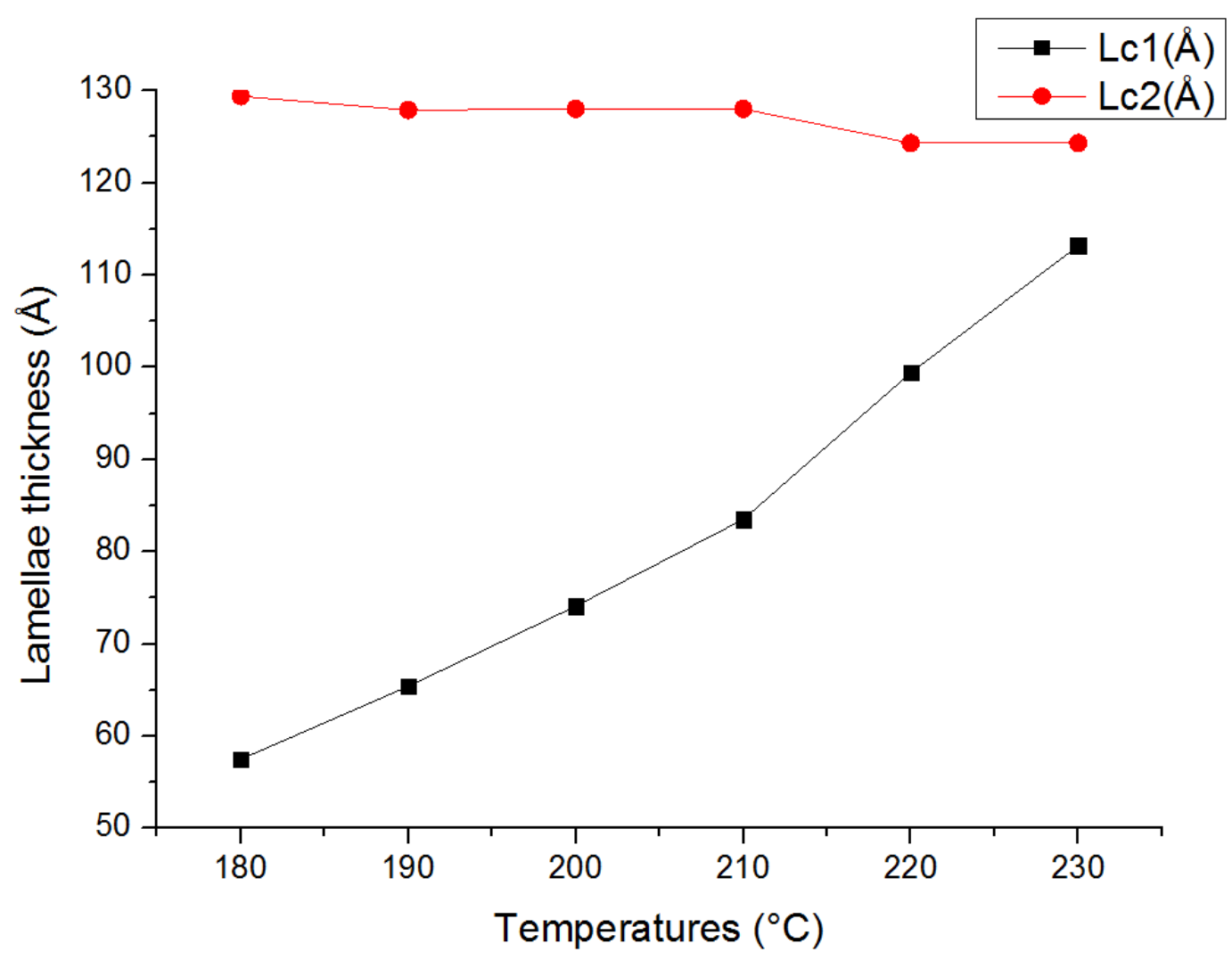

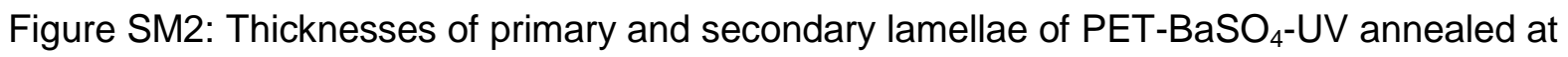
various temperatures from 180 to $230^{\circ} \mathrm{C}$ for 60 mins 


\begin{tabular}{|c|c|c|c|}
\hline $\begin{array}{c}\text { Samples } \\
\text { Untreated PET- } \\
\text { BaSO }{ }_{4} \text {-UV }\end{array}$ & $1455 \mathrm{~cm}^{-1}$ & $1473 \mathrm{~cm}^{-1}$ & $\% \mathrm{X}_{\mathrm{c}}$ \\
\hline $180^{\circ} \mathrm{C}$ & 68.3 & 31.7 & 31.7 \\
\hline $190^{\circ} \mathrm{C}$ & 66.9 & 32.6 & 32.6 \\
\hline $200^{\circ} \mathrm{C}$ & 66 & 33.1 & 33.1 \\
\hline $210^{\circ} \mathrm{C}$ & 66 & 34 & 34 \\
\hline $220^{\circ} \mathrm{C}$ & 64.5 & 34 & 35.5 \\
\hline $230^{\circ} \mathrm{C}$ & 64.1 & 35.5 & 35.9 \\
\hline
\end{tabular}

Table SM2: Crystallinity degrees of untreated and annealed PET-BaSO ${ }_{4}$-UV determined by ATR-FTIR 